\title{
Editorial
}

\section{Glioblastoma multiforme and laser interstitial thermal therapy}

\author{
J. BRADley Elder, M.D., \\ And E. Antonio Chiocca, M.D., Ph.D. ${ }^{2}$
}

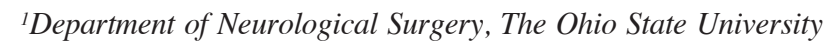
Medical Center, Columbus, Ohio; and 'Department of Neurosurgery, Brigham and Women's Hospital, and Center for Neuro-Oncology, Dana-Farber Cancer Institute, Boston, Massachusetts

A significant portion of the literature regarding treatment for patients with high-grade glioma focuses on patient populations and variables ideal for maximal intervention. Patient-specific variables such as age, performance status, anatomical tumor location, and medical comorbidities influence prognosis, which in turn influences decisions regarding surgical intervention. ${ }^{1}$ Maximal resection is associated with improved survival, but currently fewer than half of patients are candidates for open resection at presentation. ${ }^{7,8}$ This initial decision regarding surgery influences subsequent decisions regarding adjuvant therapy, and is likely to have a significant impact on the efficacy of therapy. Although clinical trials for glioblastoma multiforme (GBM) have shaped the current standard of care, in a significant portion of patients our best efforts cannot be applied because the tumor cannot be extensively resected at diagnosis.

Although clinical trials often exclude patients with poor prognostic variables such as advanced age or low Karnofsky Performance Status score, ${ }^{10}$ recent work suggests that age should not be a factor in deciding whether to pursue aggressive resection. ${ }^{6}$ However, extensive resection may be contraindicated due to other factors such as anatomical location of the tumor or medical comorbidities. These patients stand to benefit most from new surgical strategies that could provide extensive cytoreduction of the tumor. An important aspect of the clinical trial described by Dr. Sloan and colleagues ${ }^{9}$ in their paper "Results of the NeuroBlate System first-in-humans Phase I clinical trial for recurrent glioblastoma. Clinical article" is the prospect of using this technique to provide more extensive treatment for tumors in patients who were previously relegated to biopsy only.

Laser interstitial thermal therapy (LITT) has been used in cancer treatment for more than 20 years. ${ }^{3}$ Initial clinical reports and much of the current literature primarily focus on areas such as metastatic disease in the liver ${ }^{2}$ and prostate diseases such as benign prostatic hypertrophy. ${ }^{5}$ In organs such as the liver, borders of treatment can extend beyond the lesion, and damage to surrounding tissues is somewhat tolerable. In contrast, any type of treatment for a brain tumor has to be highly conformal-akin to radiosurgery treatment planning-because targeting of the therapy outside of the tumor can result in neurological morbidities, cerebrovascular sequelae or, if the treatment volume is inadequate, lack of efficacy. Previous efforts at treating brain lesions with LITT have largely been described retrospectively, with the conclusion that further technological advances leading to increasingly conformal treatments would be needed to improve LITT as an option for brain tumors. ${ }^{4}$

In this context, the clinical trial described in this issue of the Journal of Neurosurgery is a step in that direction; the authors introduce advances in LITT technology to the treatment of recurrent GBMs. Although the investigators imposed exclusion criteria common to GBM clinical trials, there is clearly potential for this treatment modality to be implemented in patients who would otherwise be relegated to biopsy, due to the minimally invasive nature of the procedure. The authors note that the primary goal of this study was demonstration of the safety and feasibility of the technique, but superiority of this procedure over biopsy alone in terms of outcome is likely, which may represent a promising potential alteration in the treatment paradigm for these patients.

The prognosis for patients with GBM remains dismal, despite significant efforts and recent progress. Much investigation has focused on treatment options after surgery, which is optimized in patients with low tumor burden. In addition, alternative treatment strategies are often only available in patients whose surgical intervention yielded gross-total or extensive resection. Less invasive surgical techniques capable of achieving extensive resection may benefit a large percentage of patients with GBM. Patients previously thought to have inoperable tumors may benefit most, not only by having their tumor removed, but by maximizing their adjuvant therapy options. Patients with poor prognostic variables, such as the elderly and those with medical comorbidities, may also demonstrate benefit. In these patients, outcomes may not equal those of patients who are candidates for maximal intervention, but could provide a step toward eliminating the prognostic disparities between these groups.

There are limitations to the technology. For instance, the occurrence of cerebrovascular complications after LITT can be devastating to the patient. In addition, this is another focal treatment and, as we know, the problem with GBM treatment is that it is an invasive disease that cannot be targeted with focal treatments. Finally, because 
expenses for new technologies are under scrutiny in terms of whether they truly provide a better outcome, the burden for LITT may be to show that the outcomes will be superior to those of other focal technologies. In GBM treatment this can become a tall order.

In spite of these limitations, the authors should be congratulated for evaluating this device in a formal prospective Phase I clinical trial rather than in the typical retrospective device evaluation "trials" commonly performed in neurosurgery. It is likely that this will become the standard for what we do and for the tools we use in the operating room.

(http://thejns.org/doi/abs/10.3171/2012.9.JNS121563)

\section{Disclosure}

The authors report no conflict of interest.

\section{References}

1. Kita D, Ciernik IF, Vaccarella S, Franceschi S, Kleihues P, Lütolf UM, et al: Age as a predictive factor in glioblastomas: population-based study. Neuroepidemiology 33:17-22, 2009

2. Mack MG, Straub R, Eichler K, Söllner O, Lehnert T, Vogl TJ: Breast cancer metastases in liver: laser-induced interstitial thermotherapy-local tumor control rate and survival data. Radiology 233:400-409, 2004

3. Masters A, Steger AC, Lees WR, Walmsley KM, Bown SG: Interstitial laser hyperthermia: a new approach for treating liver metastases. Br J Cancer 66:518-522, 1992

4. Mohammed Y, Verhey JF: A finite element method model to simulate laser interstitial thermo therapy in anatomical inhomogeneous regions. Biomed Engin Online 4:2, 2005

5. Muschter R, Whitfield H: Interstitial laser therapy of benign prostatic hyperplasia. Eur Urol 35:147-154, 1999

6. Oszvald A, Güresir E, Setzer M, Vatter H, Senft C, Seifert V, et al: Glioblastoma therapy in the elderly and the importance of the extent of resection regardless of age. Clinical article. J Neurosurg 116:357-364, 2012

7. Sanai N, Polley MY, McDermott MW, Parsa AT, Berger MS: An extent of resection threshold for newly diagnosed glioblastomas. Clinical article. J Neurosurg 115:3-8, 2011

8. Schwarzmaier HJ, Eickmeyer F, von Tempelhoff W, Fiedler VU, Niehoff H, Ulrich SD, et al: MR-guided laser irradiation of recurrent glioblastomas. J Magn Reson Imaging 22:799803,2005

9. Sloan AE, Ahluwalia MS, Valerio-Pascua J, Manjila S, Torchia MG, Jones SE, et al: Results of the NeuroBlate System first-in-humans Phase I clinical trial for recurrent glioblastoma. Clinical article. J Neurosurg [epub ahead of print April 5, 2013. DOI: 10.3171/2013.1.JNS1291]

10. Stupp R, Mason WP, van den Bent MJ, Weller M, Fisher B, Taphoorn MJ, et al: Radiotherapy plus concomitant and adjuvant temozolomide for glioblastoma. N Engl J Med 352: 987-996, 2005

\section{Response}

Andrew E. Sloan, M.D., ${ }^{1,2}$ Manmeet S. Ahluwalia, M.D., 3,4 Jose Valerio-Pascua, M.D., ${ }^{3,5,6}$ Sunil Manjila, M.D., ${ }^{1}$ Mark G. Torchia, Ph.D., 7 Stephen E. Jones, M.D., Ph.D., ${ }^{3,8}$ JefFrey L. Sunshine, M.D., Ph.D., 2,9

Michael Phillips, M.D., ${ }^{3,8}$ Mark A. Griswold, Ph.D., ${ }^{1,10}$ Mark Clampitt, R.T.(R)(MR)(CT), ${ }^{9}$ CAthy Brewer, R.N., ${ }^{3}$
JenNifer Jochum, R.N., ${ }^{1,2}$ Mary V. McGraw, ${ }^{3}$ Dawn Diorio, R.N., ${ }^{1,2}$ GaIl Ditz, R.N., ${ }^{3}$ And Gene H. Barnett, M.D., M.B.A. .,3,5 $^{2}$

\begin{abstract}
${ }^{1}$ Brain Tumor \& Neuro-Oncology Center and Department of Neurosurgery, and ${ }^{9}$ Department of Radiology, University Hospitals Case Medical Center, Seidman Cancer Center; ${ }^{2}$ Case Comprehensive Cancer Center, and ${ }^{10}$ Department of Biomedical Engineering, Case Western Reserve University School of Medicine; ${ }^{3}$ Rose Ella Burkhardt Brain Tumor and Neuro-Oncology Center, Neurological Institute, Cleveland Clinic; ${ }^{4}$ Department of Solid Tumor Oncology, Taussig Cancer Institute, Cleveland Clinic; ${ }^{5}$ Department of Neurosurgery, Cleveland Clinic; ${ }^{8}$ Department of Neuroradiology, Radiology Institute, Cleveland Clinic, Cleveland, Ohio; ${ }^{6}$ Department of Neurosurgery, Cleveland Clinic Florida, Weston, Florida; and ${ }^{7}$ Department of Surgery, University of Manitoba, Winnipeg, Manitoba, Canada
\end{abstract}

We thank Drs. Elder and Chiocca for their thoughtful and insightful comments regarding our study. As they note, although maximal resection of malignant gliomas is associated with improved outcome, the risk of resection of tumor in eloquent regions is increased and neurological deficits are associated with decreased survival. ${ }^{5,8,9}$ Indeed, the risks of complications in patients undergoing surgery for recurrent GBM, such as those in our study, is increased relative to newly diagnosed patients. ${ }^{1,6}$ Our hypothesis was that the NeuroBlate System would enable more precise ablation of tumor in patients for whom resection performed using conventional techniques was undesirable or contraindicated due to the deep or eloquent location of the tumor, or due to other factors making more aggressive approaches undesirable.

As noted by Drs. Elder and Chiocca, the invasive nature of gliomas is usually the reason for treatment failure in these patients. However, invasion is usually not well addressed by either resection or focal therapies. Thus, it is likely that in addition to direct cytoreduction of tumor, some of the benefit from resection derives from reduction of mass effect, which better enables some patients to tolerate adjuvant treatment(s). We believe that in addition to being minimally invasive, the rapid tumor thermal ablation induced by LITT may be advantageous in comparison to the more delayed and less certain cytoreduction induced by other minimally invasive therapies that use ionizing radiation, such as brachytherapy and radiosurgery. Furthermore, there is the potential for a selective hyperthermic treatment of tumor cells in the region immediately surrounding the zone of coagulation.

As the writers note, the exclusion criteria for this trial were similar to those for other minimally invasive therapies. Moreover, our subsequent experience with NeuroBlate suggests that conformality can be improved and exclusion criteria can be liberalized by using multiple trajectories (which was prohibited by the FDA for this trial). Likewise, we acknowledge that the complications noted in 2 of our patients treated at higher doses are potentially serious, but emphasize that in this Phase I dose escalation trial, application of the highest dose to the tumor margin was mandated by the study design; we believe that such complications can be largely avoided in the future by applying surgical judgment, limiting ablation to the blue thermal damage threshold line $\left(\mathrm{TD}_{\text {medium }} ; 10\right.$ minutes 


\section{Editorial}

at $43^{\circ} \mathrm{C}$ ), as well as more complete preoperative imaging with MR angiography and diffusion tensor imaging with fiber tracking.

We also agree that although we have demonstrated NeuroBlate to be feasible and safe, demonstrating efficacy and cost savings compared to other focal therapies will be necessary before this approach can be widely adopted. Brachytherapy ${ }^{3,11}$ and stereotactic radiosurgery, ${ }^{11,12}$ however, have only limited efficacy according to retrospective studies in selected populations, $, 7,11$ and the toxicity has been high. ${ }^{2,10}$ Thus, we believe that further studies of this promising technology are indicated.

\section{References}

1. Ammirati M, Vick N, Liao YL, Ciric I, Mikhael M: Effect of the extent of surgical resection on survival and quality of life in patients with supratentorial glioblastomas and anaplastic astrocytomas. Neurosurgery 21:201-206, 1987

2. Binello E, Green S, Germano IM: Radiosurgery for highgrade glioma. Surg Neurol Int 3 (Suppl 2):S118-S126, 2012

3. Chen AM, Chang S, Pouliot JS, Sneed PK, Prados MD, Lamborn KR, et al: Phase I trial of gross total resection, permanent iodine-125 brachytherapy, and hyperfractionated radiotherapy for newly diagnosed glioblastoma multiforme. Int J Radiat Oncol Biol Phys 69:825-830, 2007

4. Kondziolka D, Flickinger JC, Bissonette DJ, Bozik M, Lunsford LD: Survival benefit of stereotactic radiosurgery for patients with malignant glial neoplasm. Neurosurgery 41:776785,1997

5. McGirt MJ, Mukherjee D, Chaichana KL, Than KD, Weingart JD, Quinones-Hinojosa A: Association of surgically acquired motor and language deficits on overall survival after resec- tion of glioblastoma multiforme. Neurosurgery 65:463-470, 2009

6. Niyazi M, Siefert A, Schwarz SB, Ganswindt U, Kreth FW, Tonn JC, et al: Therapeutic options for recurrent malignant glioma. Radiother Oncol 98:1-14, 2011

7. Romanelli P, Conti A, Pontoriero A, Ricciardi GK, Tomasello F, DeRenzis C, et al: Role of stereotactic radiosurgery and fractionated stereotactic radiotherapy for the treatment of recurrent glioblastoma multiforme. Neurosurg Focus 27(6):E8, 2009

8. Sanai N, Polley MY, McDermott MW, Parsa A, Berger MS: An extent of resection threshold for newly diagnosed glioblastomas. Clinical article. J Neurosurg 115:3-8, 2011

9. Sawaya R, Hammoud M, Schoppa D, Hess KR, Wu SZ, Shi WM, et al: Neurosurgical outcomes in a modern series of 400 craniotomies for treatment of parenchymal tumors. Neurosurgery 42:1044-1056, 1998

10. Selker RG, Shapiro WR, Burger P, Blackwood MS, Arena VC, Gilder JC, et al: The Brain Tumor Cooperative Group NIH Trial 87-01: a randomized comparison of surgery, external radiotherapy, and carmustine versus surgery, interstitial radiotherapy boost, external radiation therapy, and carmustine. Neurosurgery 51:343-357, 2002

11. Sneed PK, Stauffer PR, McDermott MW, Diederich CJ, Lamborn KR, Prados MD, et al: Survival benefit of hyperthermia in a prospective randomized trial of brachytherapy boost +/hyperthermia for glioblastoma multiforme. Int J Radiat Oncol Biol Phys 40:287-295, 1998

12. Ulm AJ III, Friedman WA, Bradshaw P, Foote KD, Bova FJ: Radiosurgery in the treatment of malignant gliomas: the University of Florida experience. Neurosurgery 57:512-517, 2005

Please include this information when citing this paper: published online April 5, 2013; DOI: 10.3171/2012.9.JNS121563. 